\section{THE EFFECT OF PEEL STRESS ON THE STRENGTH OF ADHESIVELY BONDED JOINTS}

\author{
K. E. Metzinger and T. R. Guess \\ Senior Members of Technical Staff \\ Sandia National Laboratories \\ Albuquerque, New Mexico
}

\section{Abstract}

Composite wind turbine blades are often attached to a metallic structure with an adhesive bond. The objective of this investigation is to determine which parameters affect the durability of these adhesively bonded joints. The composite-to-steel joint considered in this study typically fails when the adhesive debonds from the steel adherend. Previously, this joint was monotonically loaded in either compression or tension. Compressive and tensile axial loads of the same magnitude produce adhesive stresses with very similar magnitudes but opposite signs. (For the joint considered, tensile loads produce compressive peet stresses in the adhesive at the location where debonding initiates.) The tensile specimens failed at much higher loads, establishing that the sign of the adhesive peel stresses strongly influences the single-cycle strength of these joints. Building on this earlier work, this study demonstrates that the adhesive peel stresses are also critical for fatigue loading. The results of low-cycle (axial) and highcycle (bending) fatigue tests are presented. To complement the test results, finite element analyses demonstrate the localized nature of the peel stresses that develop in the adhesive. In addition, these analyses are used to investigate some of the causes of these peel stresses.

\section{Introduction}

When adhesively bonded lap joints are utilized as blade attachments in a wind turbine, the satisfactory performance of these joints is critical to the viability of the turbine. In the interest of improving the durability of these joints, a series of tests and analyses has been conducted. The first goal of this effort is to establish which parameters affect the performance of these joints for both single-cycle and fatigue loading. Once this objective is met, it is anticipated that design improvements will be achieved by using analyses to cull various alternatives and tests to validate the most promising candidates.
Axially-loaded specimens were utilized in the previously reported single-cycle tests ${ }^{1}$. These specimens were loaded in compression or tension with a standard electrohydraulic test frame until either the adhesive bond or the composite adherend completely failed. In this study, the lowcycle fatigue tests used the same specimen geometries and test frame as the single-cycle tests. However, the low-cycle fatigue tests were terminated when the adhesive was determined using ultrasonic inspection - to have partially debonded from the steel adherend. The high-cycle fatigue tests of the joint considered in this study subject a specimen to bending loads utilizing an electromechanical shaker table (for the alternating loads) and bungee cords (for the mean loads). During these tests, the alternating loads were less than the mean loads. Thus, one half of each specimen remained in compression and the other half in tension throughout the test. As with the axial fatigue tests, the bending tests were terminated when the adhesive partially debonded from the steel adherend. Figure 1 shows a schematic of the compressive (axial) and the bending specimens. The tensile (axial) specimens are the same as the bending specimens with two exceptions. The steel adherends are 4 inches shorter and have internal threads rather than pins at the ends. The adhesive bonds are 3.0 inches long and 0.1 inches thick in all of the specimens.

For the same joint geometry, a compressive load and a tensile load of the same magnitude will produce adhesive stresses and strains with similar magnitudes. (Slight differences exist due to nonlinear geometric effects.) In this paper, the equivalent plastic strain - which is always positive will be used to represent the magnitude of the adhesive strains. Although the peel stresses that develop in the adhesive where the debonding initiates will be of similar magnitude, they will be of opposite sign. Thus, the results of the compressive and tensile tests should be comparable or quite different depending on whether the plastic strain or the peel stress, respectively, is the most important 


\section{DISCLAIMER}

This report was prepared as an account of work sponsored by an agency of the United States Government. Neither the United States Government nor any agency thereof, nor any of their employees, make any warranty, express or implied, or assumes any legal liability or responsibility for the accuracy, completeness, or usefulness of any information, apparatus, product, or process disclosed, or represents that its use would not infringe privately owned rights. Reference herein to any specific commercial product, process, or service by trade name, trademark, manufacturer, or otherwise does not necessarily constitute or imply its endorsement, recommendation, or favoring by the United States Government or any agency thereof. The views and opinions of authors expressed herein do not necessarily state or reflect those of the United States Government or any agency thereof. 


\section{DISCLAIMER}

\section{Portions of this document may be illegible in electronic image products. Images are produced from the best available original document.}


parameter influencing failure. In the previous single-cycle axial tests, the tensile strengths were much greater than the compressive strengths. Indeed, the tensile specimens (which develop compressive peel stresses in the adhesive) actually failed in the composite - not in the bond itself. This dramatic difference indicated that the adhesive peel stress is key to predicting the singlecycle strength of these joints. In this study, the results of low-cycle (axial) and high-cycle (bending) fatigue tests indicate that the peel stress remains more influential than the plastic strain in these regimes as well.

After the importance of the adhesive peel stress is established, finite element analyses are employed to better understand these stresses. The localized nature of the peel stresses is demonstrated and some of the causes of these peel stresses are addressed. Specifically, the Poisson effect of the adhesive and the adherends as well as the stiffness mismatch between the adherends are investigated.

\section{Experiments}

\section{Specimen Fabrication}

Prior to fabrication, the composite (E-glass fabric/ epoxy) and steel adherends were lightly sand blasted, sprayed with isopropyl alcohol and wiped with lint-free cloth. The plastic spacers which are used to fix the location of the bond ends also align the centerlines of the adherends. The adhesive (Hysol EA-9394) was injected into the joints and allowed to cure at room temperature for one week before the plastic spacers were removed. For the double-jointed specimens, the same process is repeated for the second joint. Note that each compressive specimen has one, joint the tensile and bending specimens each have two. (Using double-jointed specimens for the tensile and bending tests simplifies the required test fixtures.)

\section{Axial Tests}

The axial specimens were tested in an electrohydraulic test frame. Figure 2 shows a compressive specimen between two platens. The tensile specimens were attached to the test frame with eyebolts which were screwed into the threaded ends of the steel adherends. The composite adherend of each specimen was instrumented with three strain gages - equally spaced along the circumference - to assess the uniformity of the loading.

Figure 3 shows the failure loads previously recorded for the single-cycle tests ${ }^{1}$. Note that the tensile specimens failed at much higher levels than the compressive specimens. For the compressive specimens, failure occurred abruptly when the adhesive completely debonded from the steel adherend. However, the levels shown for the tensile specimens represent the applied load when the composite adherend failed. The adhesive didn't actually debond from the steel. Recall that each tensile specimen has two joints. Thus, four joints were loaded in tension to over $70000 \mathrm{lb}$ without debonding.

Figure 4 shows the results of the low-cycle fatigue tests. Each data point represents the number of cycles a joint withstood for a given loading cycle before the initial adhesive debonding was observed. It should be noted that the initial adhesive debonding always occurred at the end of the bond which corresponds to the end of the steel adherend. The compressive and tensile specimens remained in compression and tension, respectively, throughout the tests. The magnitude of the peak load was 10 times the magnitude of the minimum load for all of the specimens. Both joints of the tensile specimens were inspected for debonding throughout the tests. Thus, each tensile specimen produced two data points. Clearly, in this regime, the tensile specimens are more durable than the compressive specimens. Thus, in low-cycle $\left(-10^{3}\right.$ to $10^{5}$ ) fatigue, the adhesive peel stress remains more influential than the plastic strain. It should be noted, however, that the adhesive did debond from the steel adherends in the tensile specimens. This failure mechanism differs from the one observed in the single-cycle tests.

\section{Bending Tests}

Figure 5 shows the setup used for the high-cycle fatigue testing. The pins on both ends of the specimen fit inside lubricated composite bushings which were inserted into steel cylinders. In turn, these cylinders were clamped into the aluminum fixture which was attached to the shaker table. Copper tape was applied to the composite where the kevlar strap loops around the specimen to reduce the frictional heating that occurs at this location. Fans were also utilized to minimize any heating of the specimen due to the cyclic 
deformations. The low spring stiffness $(\sim 100 \mathrm{lb} / \mathrm{in})$ of the bungee cords allowed a nearly constant lateral load to be applied to the center of a specimen as it vibrated due to the input from the shaker table. Strain gages were attached to the top and bottom of each composite adherend at an axial location near the middle of both of the bonds. All the specimens were subjected to a mean load of $750 \mathrm{lb}$ and a $200 \mathrm{~Hz}$ alternating load. The alternating load was achieved by maintaining a sinusoidal $(+/-50 \mathrm{~g})$ acceleration at the base of the aluminum fixture.

Figure 6 shows the strain data measured by the top and bottom gage on a typical joint. Although the input was sinusoidal and the response of the specimens consisted primarily of the first bending mode, the second bending mode was also excited. Note that the strain magnitudes are plotted. The strains measured by the bottom gage are compressive. (Tensile adhesive peel stresses develop on the bottom of the specimens at the bond end where debonding was observed in the axial fatigue tests.) While the peak strains are comparable, the alternating strains on the bottom (compressive) side are slightly lower. The differences in the magnitudes of the alternating strains may be due to the test fixture or a difference in the response of the materials to tensile and compressive loads. Previous finite element analyses ${ }^{1}$ demonstrated that the wrap angle of the kevlar strap around the composite adherend could affect the relative magnitudes of the mean strains on the top and bottom of the specimen and this effect was later observed in the laboratory. Although the measured composite strains are not identical, the adhesive strains on the top side of the specimen should have similar peak strains and a larger alternating component. Thus, if only the magnitudes of the adhesive strain were important, adhesive debonding should occur on the top side of the specimens as often as on the bottom.

Figure 7 shows the results of the high-cycle fatigue tests. Several points should be made regarding this data. As with the low-cycle tests, each filled data point represents the number of cycles a joint withstood before the initial adhesive debonding was observed. At this point, the debonded region extends over a very small portion ( 0.5 in $^{2}$ or less) of the originally bonded region. In the eight specimens in which the adhesive debonded from the steel adherend, the debonding always occurred on the compressive side. This result is consistent with the results of the single-cycle and low-cycle tests. Also note the significant scatter in the data. While three joints had started to debond by half a million cycles, two joints showed no signs of debonding after 14 million cycles. It is not surprising that the bending fatigue tests have more scatter than the axial fatigue tests since only a small portion of the adhesive bonds in the bending specimens experience the maximum stresses. (The adhesive bonds of the uniformly loaded axial specimens experience the maximum stresses along the entire circumference of the bond.)

\section{Analyses}

\section{Finite Element Models}

Figure 8 shows the axisymmetric finite element mesh used for the compressive specimen. The adhesive layer has sixteen elements through its thickness. The finite element mesh of the tensile specimen employs a symmetry plane and is similar to the mesh shown in Figure 8. The only other difference is the lengths of the adherends. Both meshes are comprised of eight-node biquadratic, reduced integration, axisymmetric solid elements (CAX8R). All of the analyses - which incorporate nonlinear geometric effects and allow for plastic deformations in the adhesive - were performed with ABAQUS $^{2}$. The isotropic material properties used for the adhesive ${ }^{3}$ and the steel are listed in Table 1. Generic values were used for the steel. The adhesive properties correspond to a high strength, room-temperature curing paste adhesive. The orthotropic material properties ${ }^{4}$ listed in Table 2 represent a plain weave E-glass fabric/epoxy composite. The subscripts $r, a$, and $t$ in Table 2 refer to the radial, axial, and tangential directions, respectively.

\section{Results}

Figures 9 and 10 show the peel (normal) stresses and plastic strains that develop in the adhesive at the adhesive/steel adherend interface, respectively, for an axial load of $35000 \mathrm{lb}$. Note that the high peel stresses at the bond ends are quite localized. Although the calculated values are dependent upon the corresponding finite element meshes, the same discretization was used for the compressive and tensile specimens. The end of the bond where failure initiates (the right end in Figure 8) corresponds to an axial bond location of 3.0 inches. Note that the adhesive yielding is similar for 
the compressive and tensile specimens. Although the peel stresses have opposite sign, their magnitudes are also similar. The small differences that exist in the magnitudes arise from nonlinear geometric effects and may not be significant. Regardless, the plastic strain in the adhesive of a tensile specimen is at least as great as that in a compressive specimen. Thus, if the adhesive yielding were the key to the joint strength, the tensile specimens should not be significantly stronger than the compressive specimens. Given the experimental results in which the tensile strengths were considerably greater than the compressive strengths, it is clear that the peel stress is a key parameter affecting the single-cycle and low-cycle fatigue strengths of these joints. Furthermore, the bending specimens only debonded on the compressive side - indicating that the peel stress remains important in high-cycle fatigue as well. Although the plastic strain in the adhesive isn't as important as the peel stress, debonding was observed in the low-cycle tensile tests at a location where significant plastic strains and compressive peel stresses exist in the adhesive. Recall, however, that the low-cycle compressive tests (which develop comparable plastic strains and tensile peel stresses at this location) debonded much quicker. Thus, tensile peel stresses in the adhesive accelerate the debonding process, but are not required for debonding to occur.

With the importance of the adhesive peel stress established, attention can now be focused on the causes of these peel stresses. An examination of the material properties and the joint geometry reveals that the radial expansion of the composite adherend (due to the Poisson effect) would be several times larger than that of the steel adherend for a given compressive load ; if there was no restraints on the adherends. Of course, in an actual joint, each adherend is influenced by the other adherend and the adhesive. Still, the Poisson effect would be expected to cause peel stresses in the adhesive. To assess the importance of this effect, the analysis of the compressive specimen was rerun with the Poisson's ratios of all three materials set to zero. Figure 11 compares the result of this analysis with the original analysis. It is clear that the Poisson effect contributes significantly to the adhesive peel stresses. However, even if this effect could be eliminated, localized peel stresses would still develop at the bond ends.
A more realistic modification is now considered. The inner radius of the steel adherend is increased from 0.875 to 1.117 inches. This thin steel adherend has the same axial stiffness as the composite adherend. Furthermore, the unrestrained radial expansion of the composite adherend would be slightly less than that of this thin steel adherend. Figure 12 compares the peel stresses that would develop with this adherend with those associated with the original adherend. The high tensile peel stresses at the location where debonding initiates are reduced significantly by thinning the steel adherend. While this is encouraging, two practical problems would arise with this modification. First, the stability and durability of this rather thin steel adherend would be marginal at best. Second, large compressive peel stresses develop on the other end of the bond. Thus, large tensile peel stresses would develop at this location when the joint was loaded in tension. Either of these problems could result in degraded rather than enhanced durability. However, it may be possible to reduce the high tensile peel stresses in the adhesive and avoid these problems by tapering the steel adherend in the bond region. Certainly, a tapered steel adherend merits further investigation.

\section{Summary}

The durability of adhesively bonded lap joints directly affects the viability of wind turbines that utilize these joints as blade attachments. The first objective of this study was to establish which parameters affect the performance of these joints. Single-cycle, low-cycle and high-cycle fatigue tests established that the peel stress in the adhesive is the key parameter affecting the strength of the tubular lap joints considered in this study. Finite element analyses were then utilized to demonstrate the localized nature of these peel stresses and to assess how the Poisson effect contributes to them. Finally, a thinner steel adherend was shown to lower the adhesive peel stresses. While a uniformly thin steel adherend may not be practical, it may be possible to achieve the same result with a tapered adherend. 


\section{Acknowledgments}

M. E. Stavig assisted with the axial tests of the joints. D. W. Kelton improved the bending test setup. C. D. D'Spain conducted the bending tests. This work was performed at Sandia National Laboratories, which is operated for the U.S. Department of Energy under Contract No. DEAC04-94AL85000.

\section{References}

1. K. E. Metzinger and T. R. Guess, "Single-Cycle and Fatigue Strengths of Adhesively Bonded Lap Joint," 36th AIAA Aerospace Sciences Meeting and Exhibit, Reno, Nevada, January 1998.

2. ABAQUS/Standard, Version 5.7.

3. T. R. Guess, E. D. Reedy, Jr., and M. E. Stavig, "Mechanical Properties of Hysol EA-9394 Structural Adhesive," SAND95-0229, Sandia National Laboratories, Albuquerque, New Mexico, February 1995.

4. T. R. Guess, E. D. Reedy, Jr., and A. M. Slavin, "Testing Composite-to-Metal Tubular Lap Joints," Journal of Composites Technology \& Research, Vol. 17, No. 2, April 1995.
Table 1: Isotropic Material Properties

\begin{tabular}{|c|c|c|}
\hline Material & $\begin{array}{c}\text { Elastic } \\
\text { Modulus (psi) }\end{array}$ & $\begin{array}{c}\text { Poisson's } \\
\text { Ratio }\end{array}$ \\
\hline Adhesive & $6.0 \times 10^{5}$ & 0.37 \\
\hline Steel & $3.0 \times 10^{7}$ & 0.30 \\
\hline Material & $\begin{array}{c}\text { Yield } \\
\text { Strength (psi) }\end{array}$ & $\begin{array}{c}\text { Hardening } \\
\text { Modulus (psi) }\end{array}$ \\
\hline Adhesive & $4.0 \times 10^{3}$ & $3.0 \times 10^{5}$ \\
\hline Steel & - & - \\
\hline
\end{tabular}

Table 2: Composite Orthotropic Material Properties

\begin{tabular}{|c|c|c|}
\hline$E_{\mathrm{r}}(p s i)$ & $E_{\mathrm{a}}$ (psi) & $E_{\mathrm{t}}(p s i)$ \\
\hline $1.45 \times 10^{6}$ & $3.26 \times 10^{6}$ & $4.06 \times 10^{6}$ \\
\hline \hline$v_{\mathrm{ra}}$ & $v_{\mathrm{rt}}$ & $v_{\mathrm{at}}$ \\
\hline 0.10 & 0.10 & 0.17 \\
\hline \hline $\mathrm{G}_{\mathrm{ra}}(\mathrm{psi})$ & $\mathrm{G}_{\mathrm{rt}}(\mathrm{psi})$ & $\mathrm{G}_{\mathrm{at}}(\mathrm{psi})$ \\
\hline $7.25 \times 10^{5}$ & $7.25 \times 10^{5}$ & $7.25 \times 10^{5}$ \\
\hline
\end{tabular}



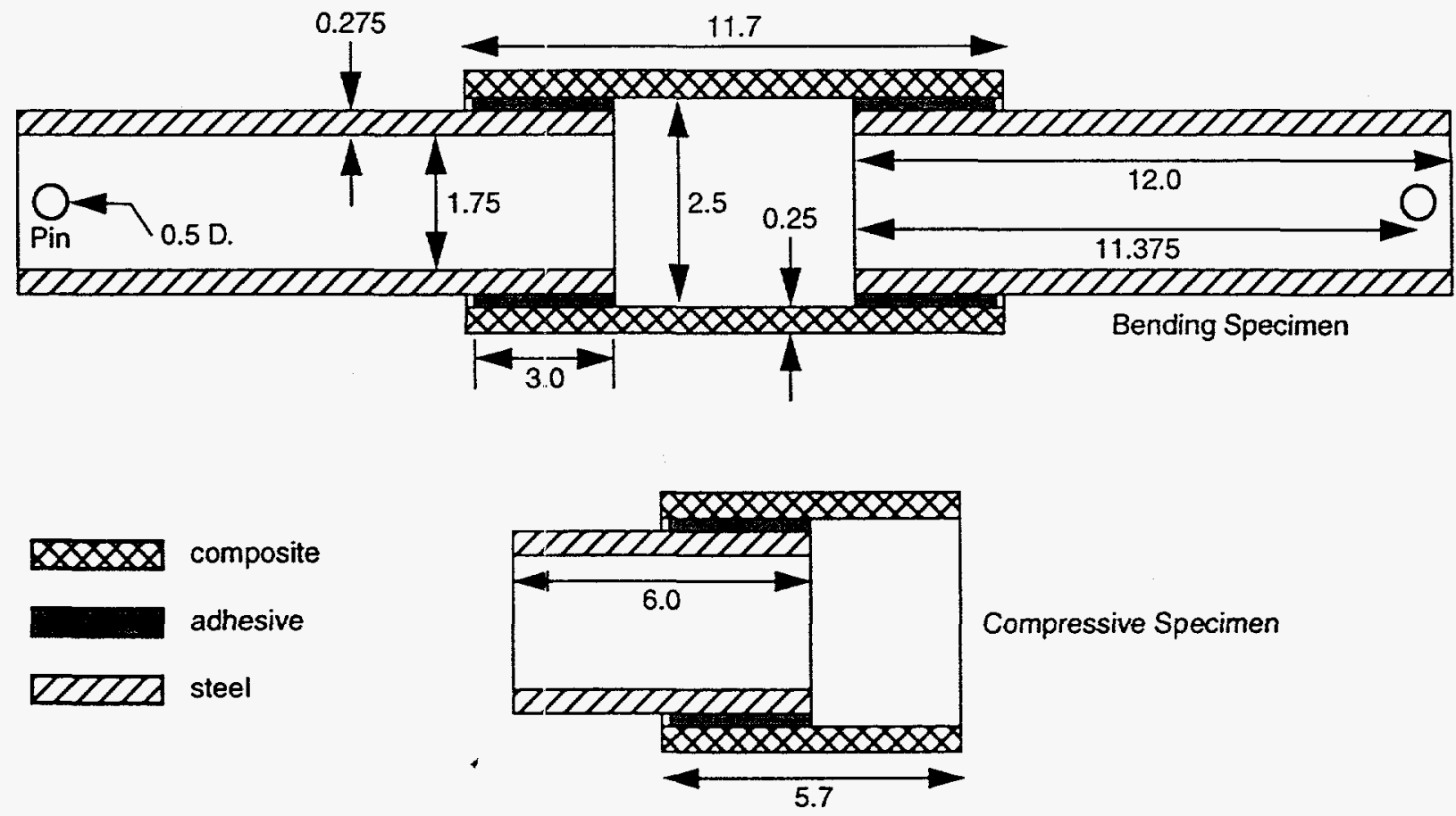

Figure 1. Schematic of Jont Geometries (Cut-away View, Dimensions in Inches)

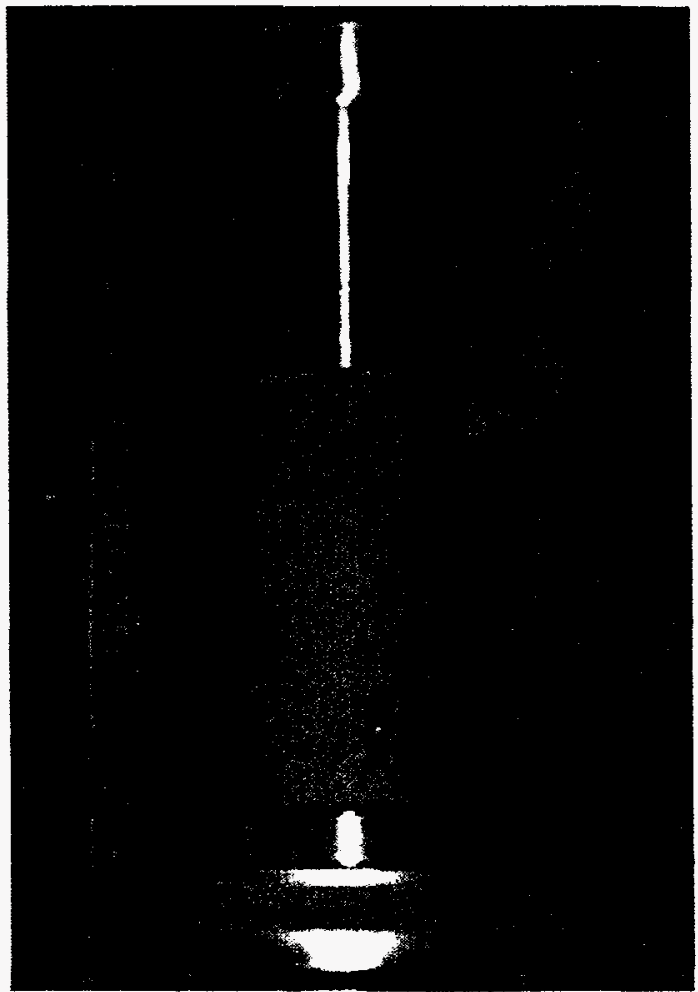

Figure 2. Axial Test Setup (Compressive Specimen) 


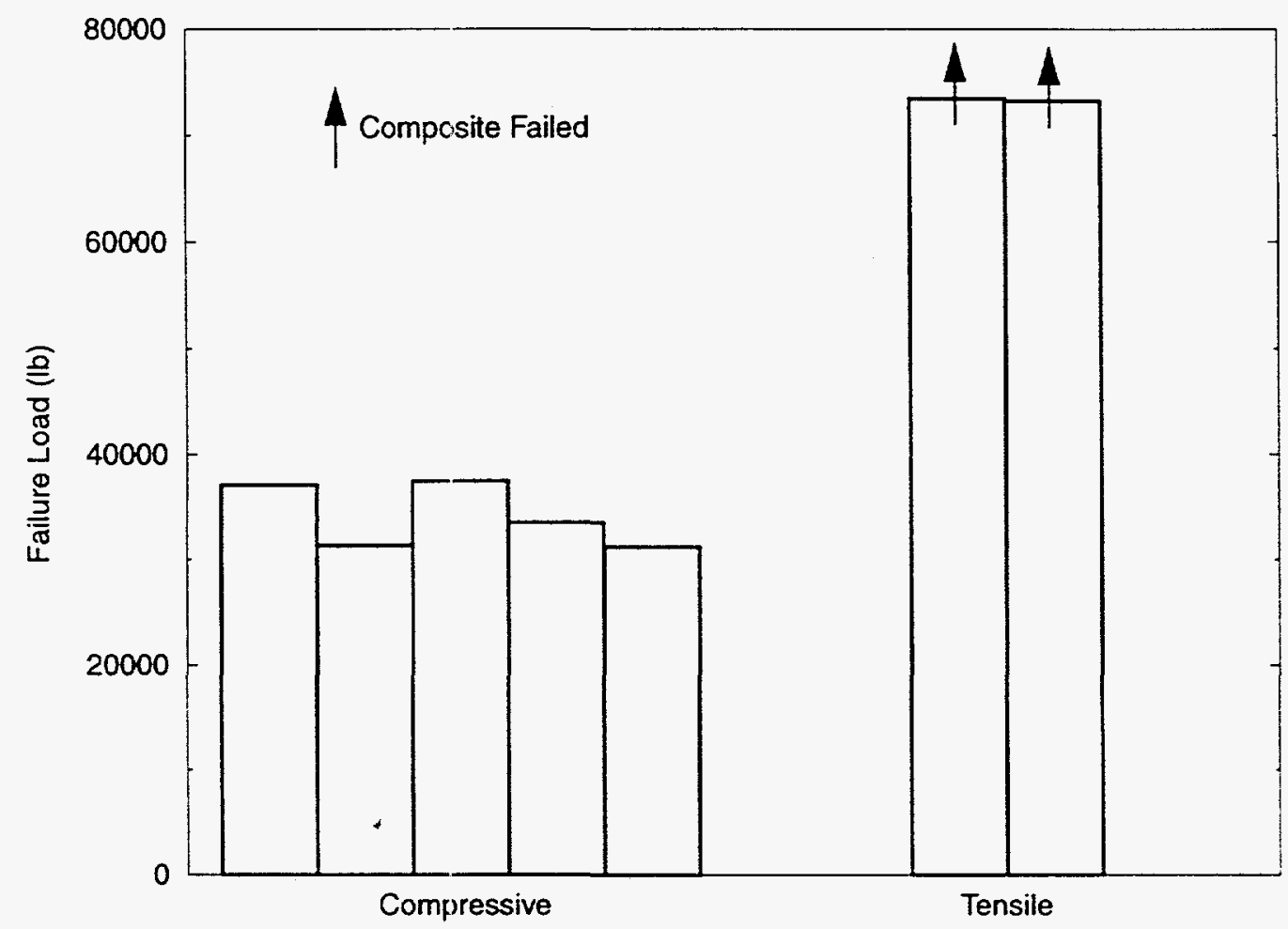

Figure 3. Single-Cycle (Axial) Failure Loads

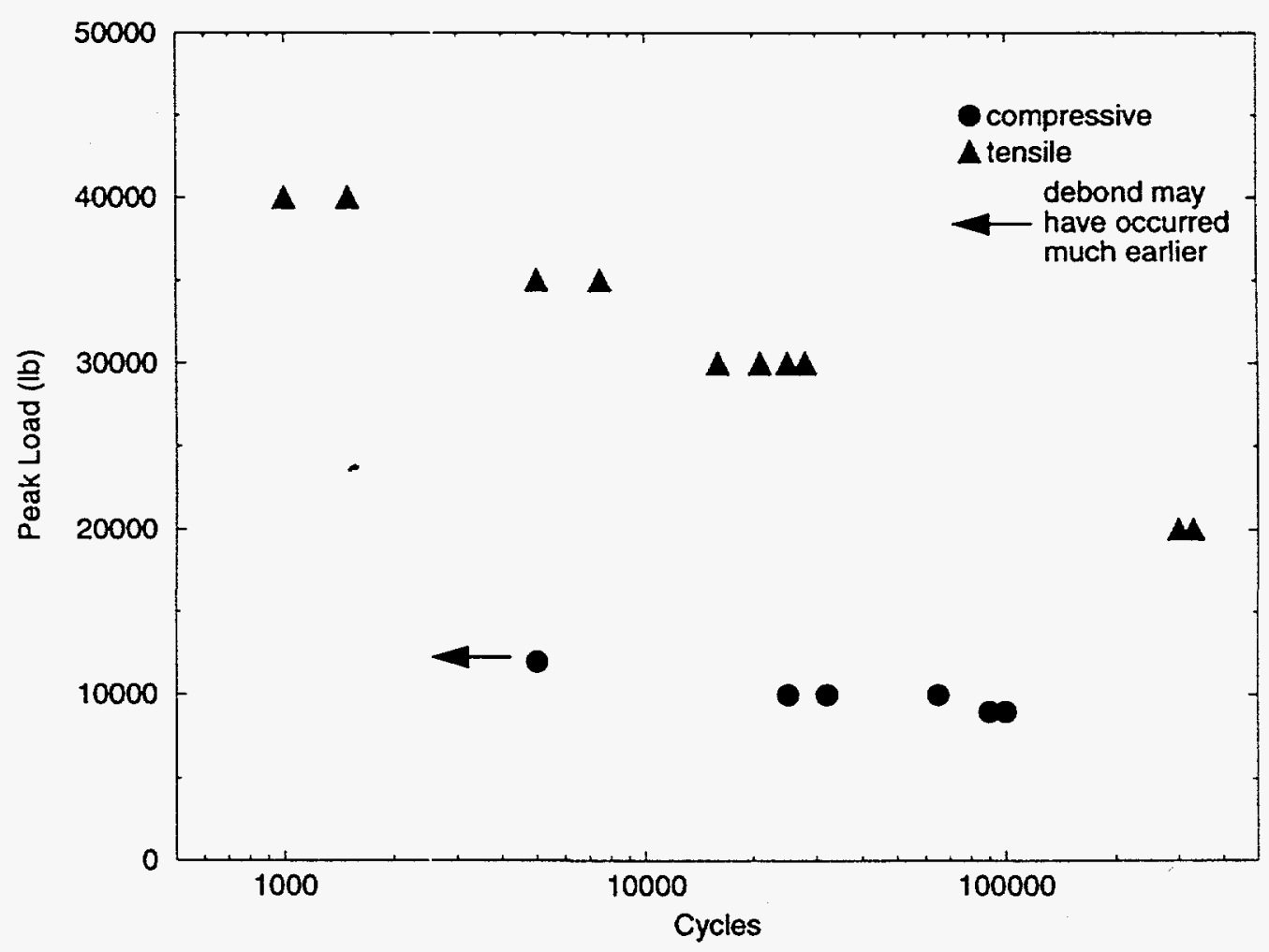

Figure 4. Low-Cycle (Axial) Fatigue Results 


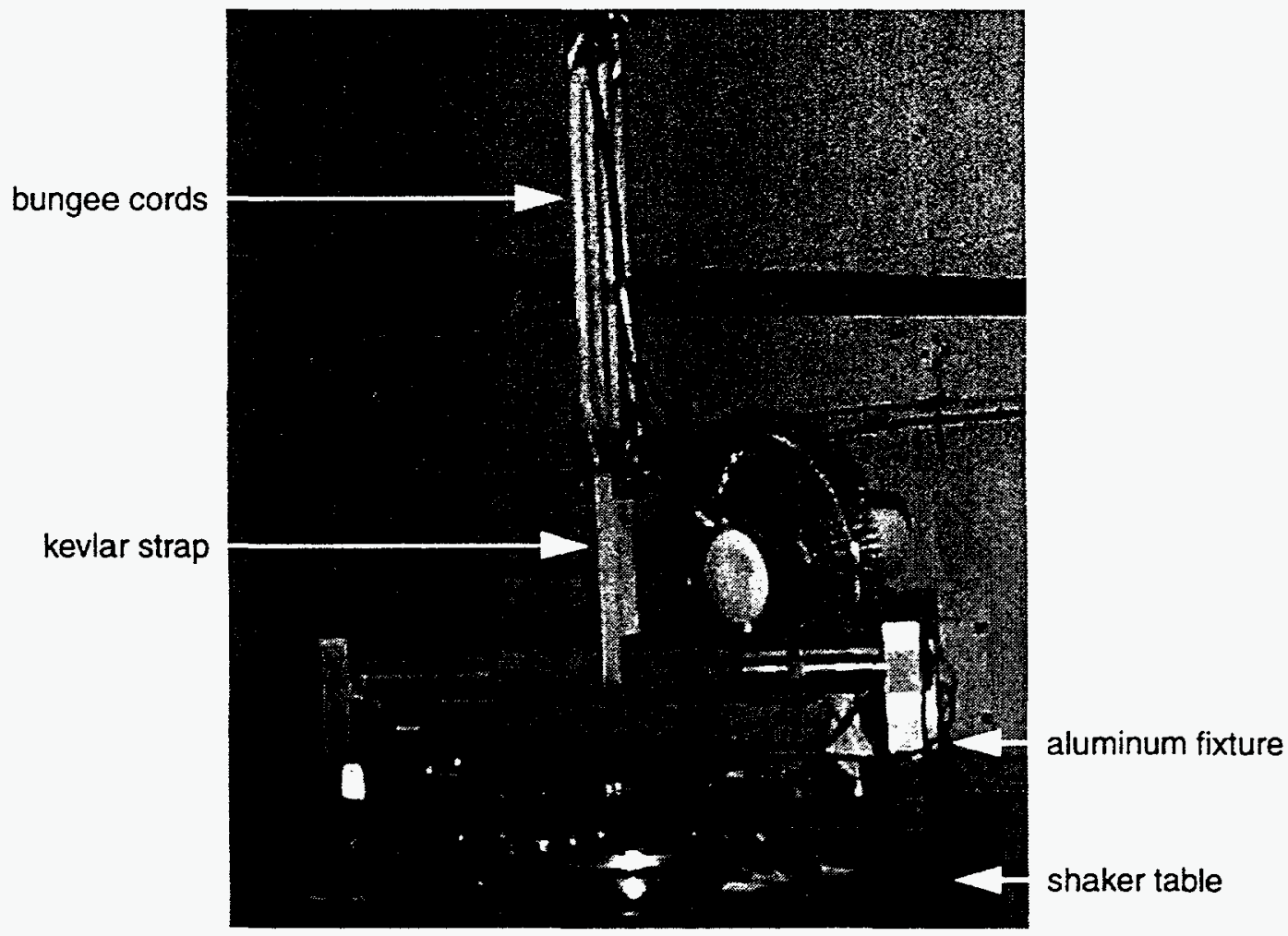

Figure 5. Bending Test Setup

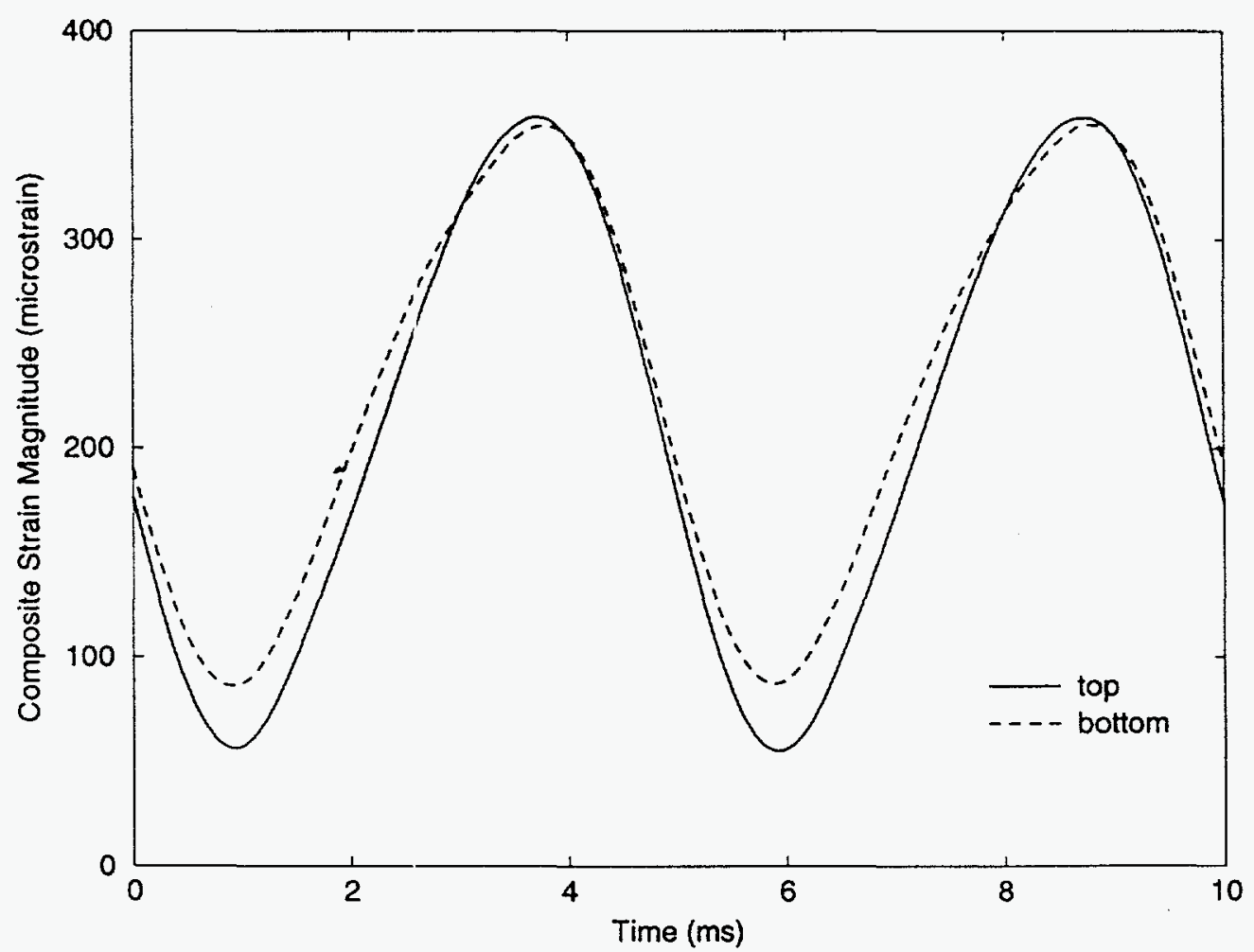

Figure 6. Strain Gage Data (Composite Adherend) 


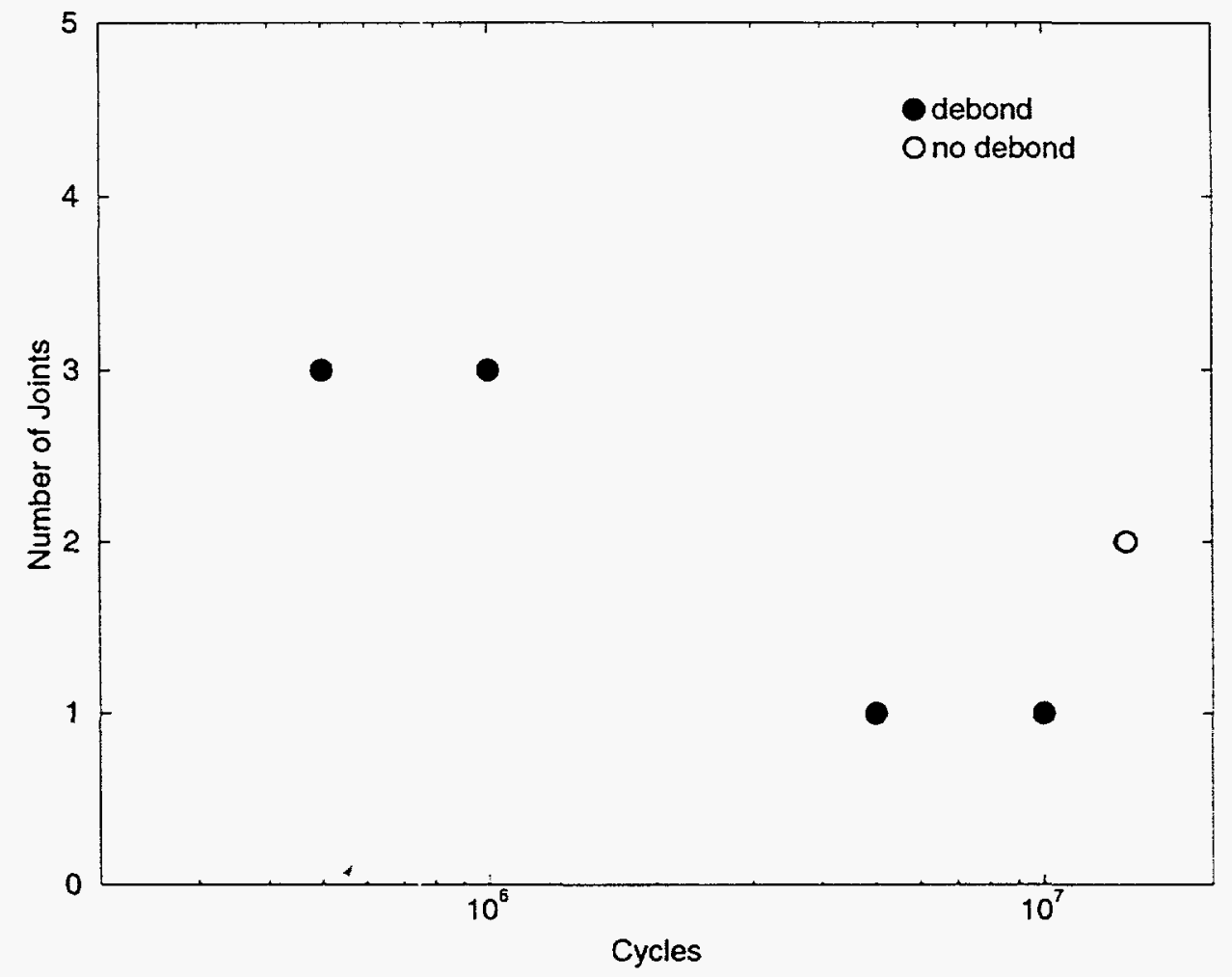

Figure 7. High-Cycle (Bending) Fatigue Results

Centerline

Steel

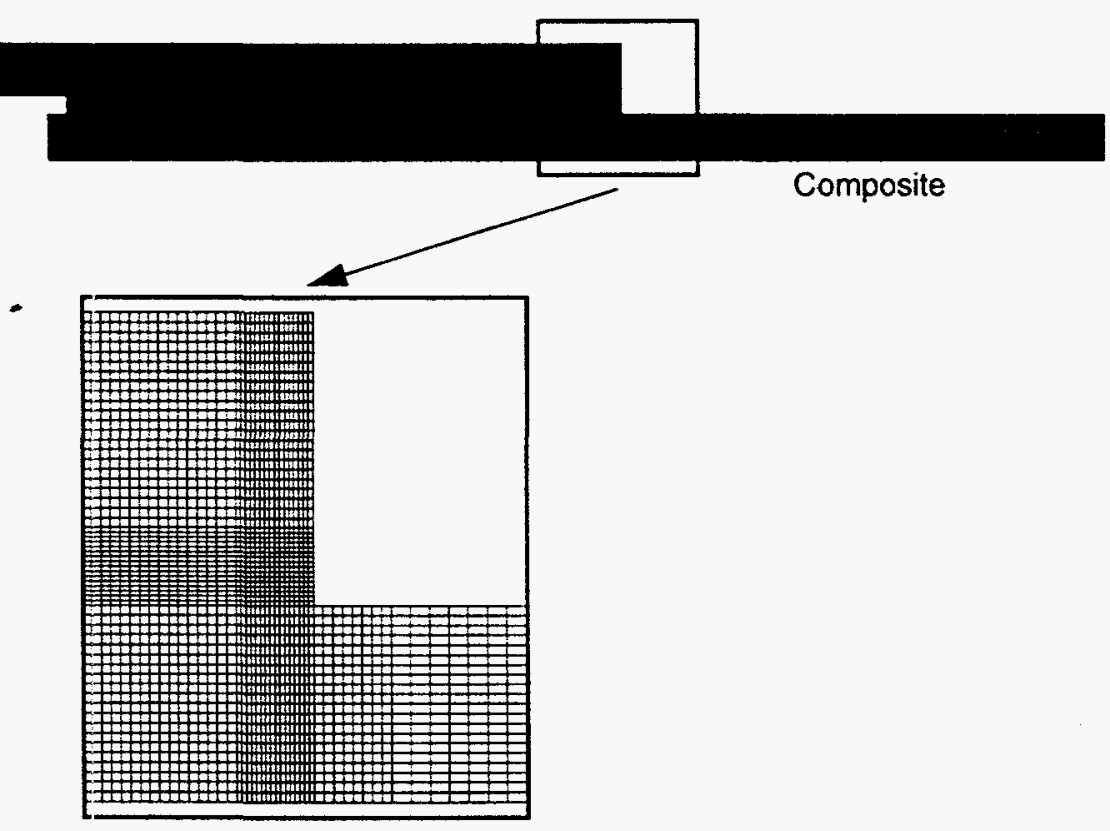

Figure 8. Axisymmetric Finite Element Mesh (Compressive Specimen) 


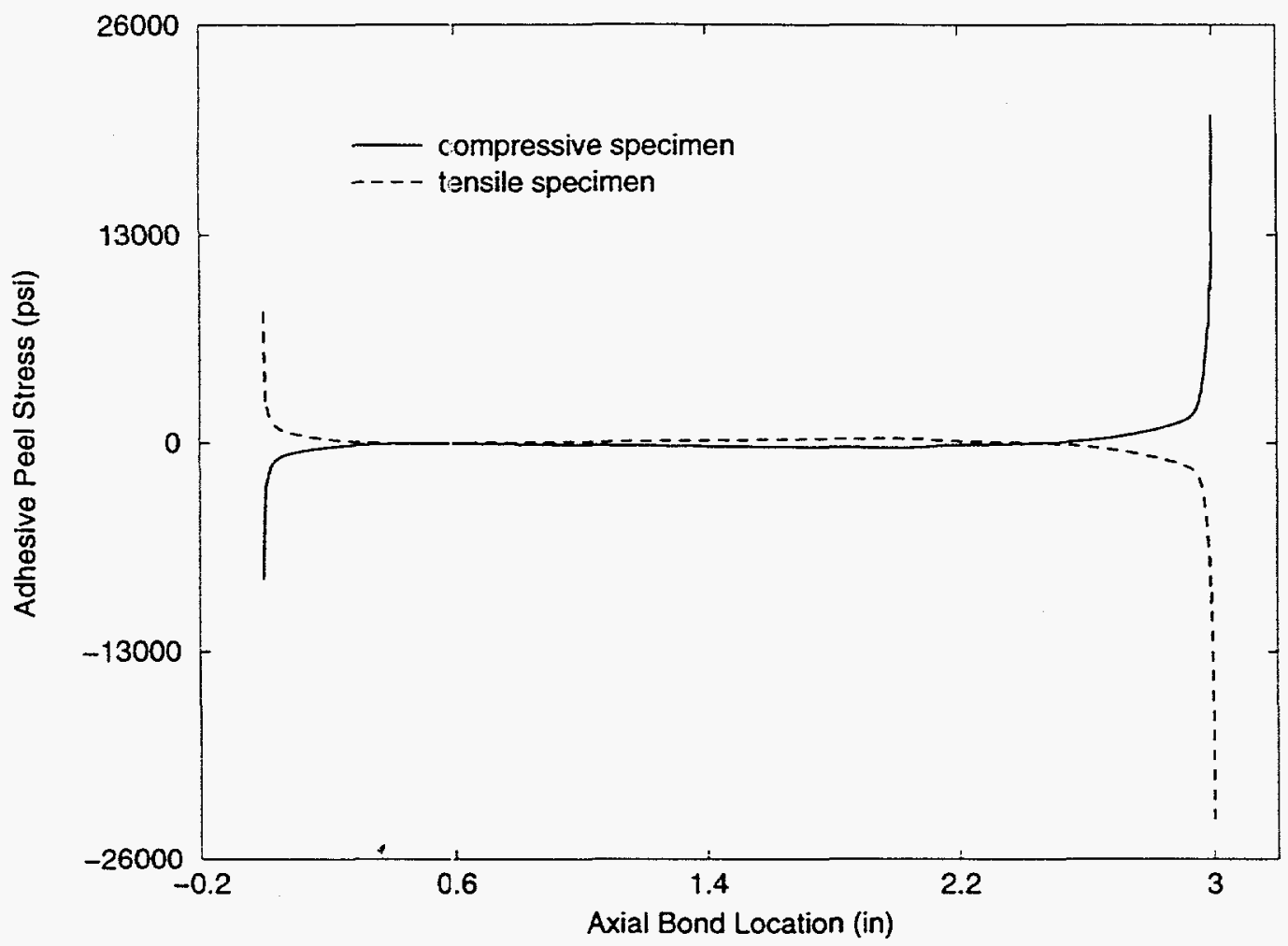

Figure 9. Adhesive Peel Stress as a Function of Load Direction

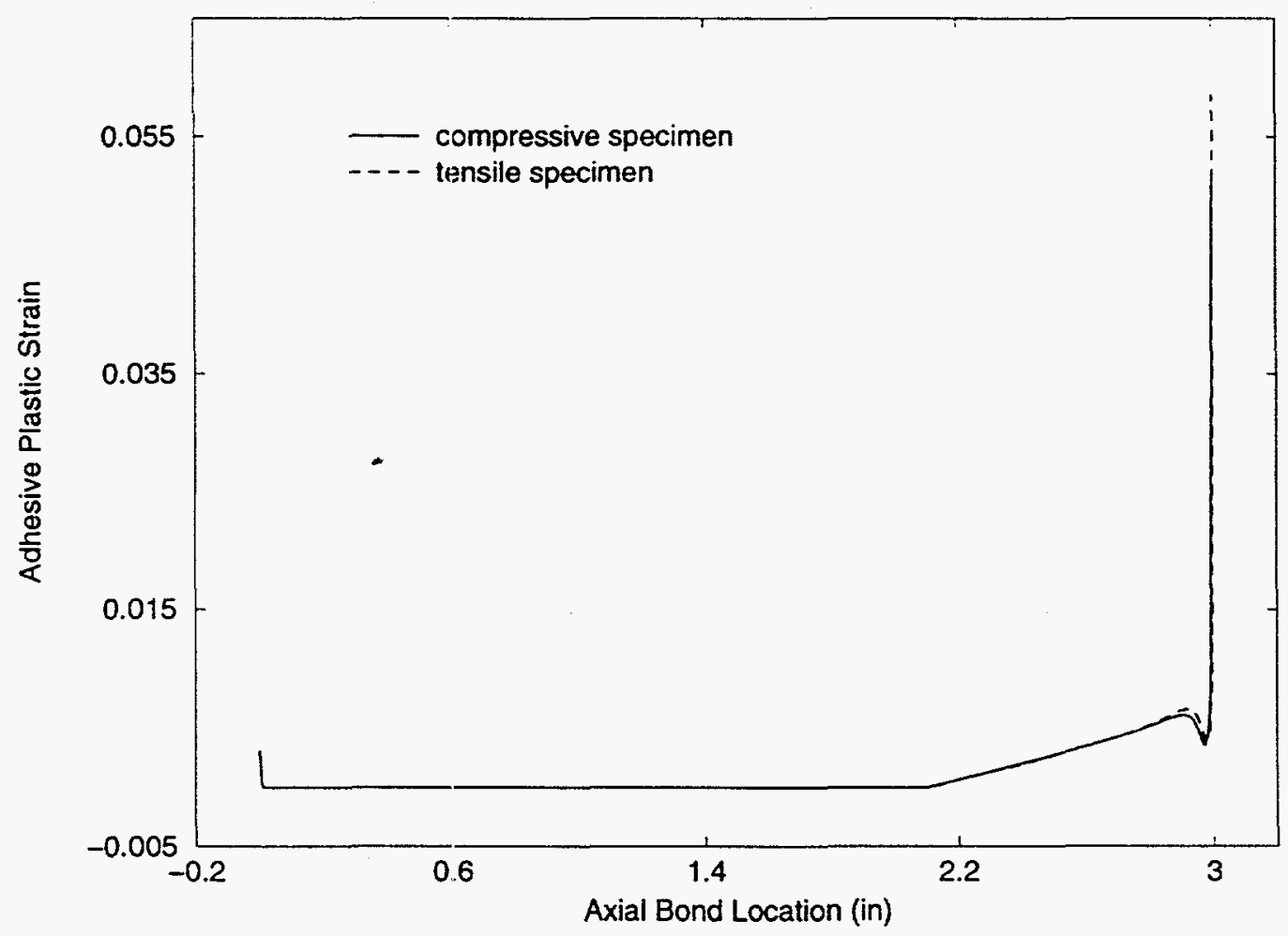

Figure 10. Adhesive Plastic Strain as a Function of Load Direction 


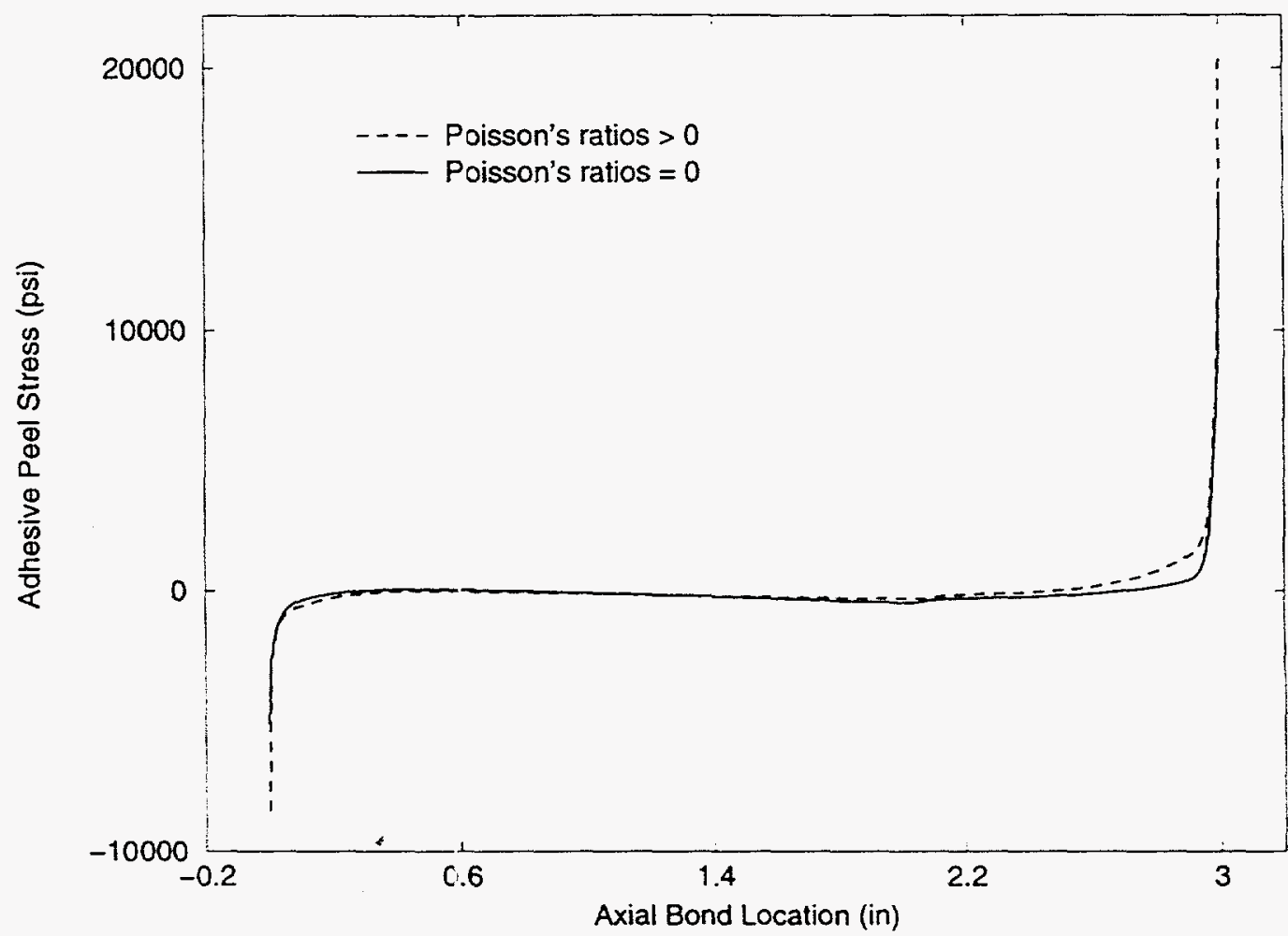

Figure 11. Adhesive Peel Stress as a Function of Poisson's Ratio - Compressive Specimen

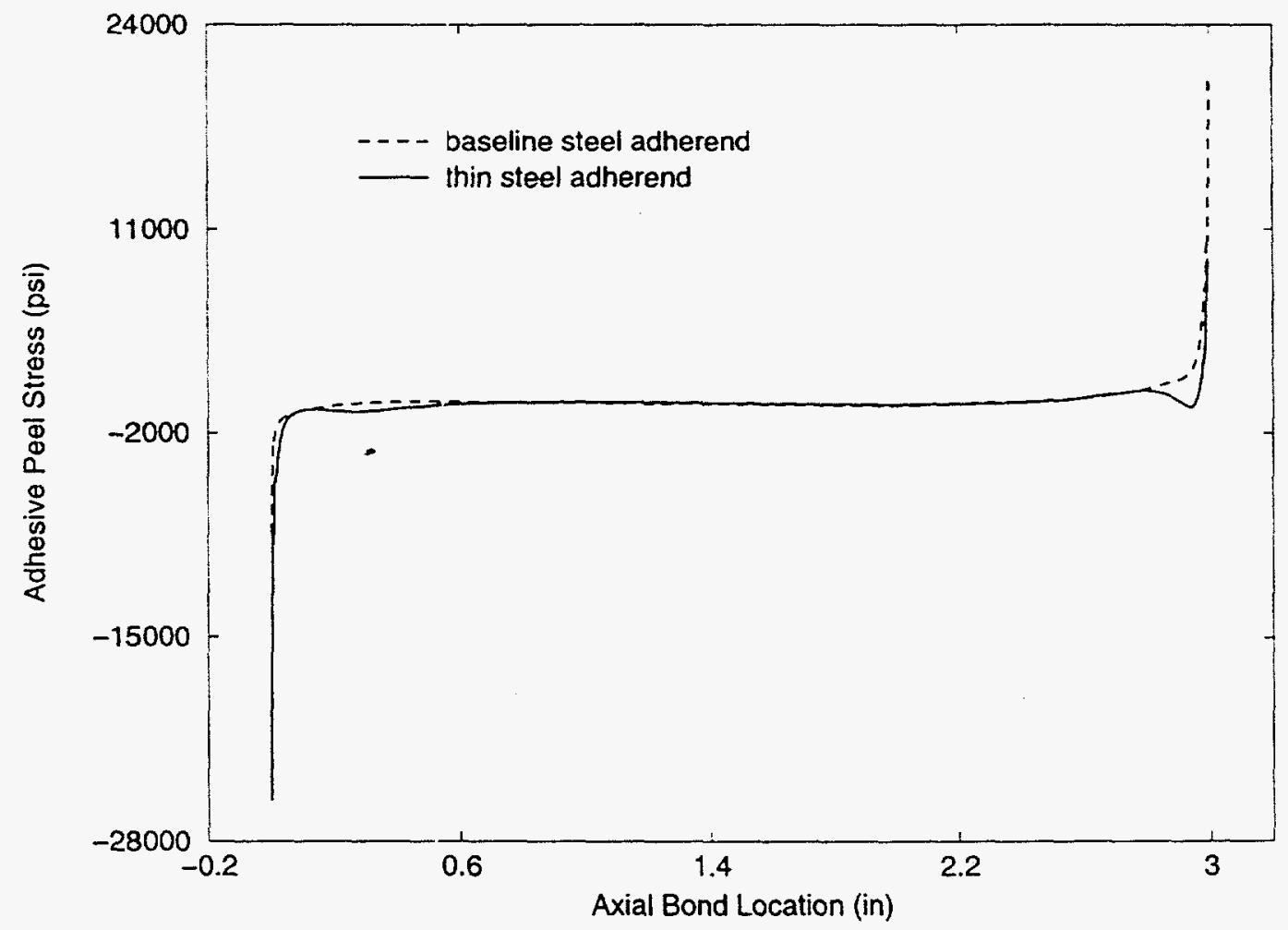

Figure 12. Adhesive Peel Stress as a Function of Steel Adherend Thickness - Compressive Specimen 